\title{
Copper-Catalyzed Asymmetric Synthesis of Dihydropyridines
}

dihydropyridines

asymmetric synthesis

piperidines

indolizidine 167B
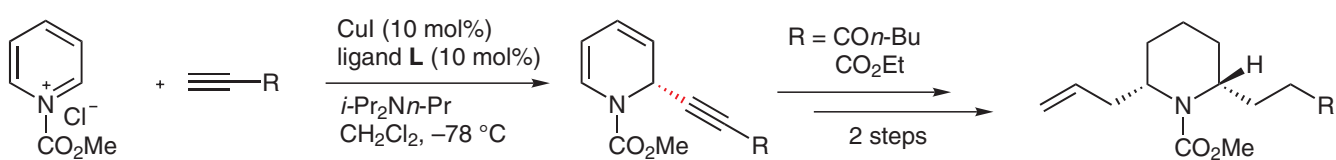

$63-81 \%$

$1-99 \%$ ee 10 examples

$66-68 \%$ over 2 steps

$\mathrm{R}=\mathrm{CO}_{2} \mathrm{Me}, \mathrm{CO}_{2} \mathrm{Bn}, \mathrm{COMe}, \mathrm{COEt}$ $\mathrm{CO}$ - $\mathrm{Bu}, \mathrm{CO}\left(\mathrm{CH}_{2}\right)_{4} \mathrm{Me}, \mathrm{CO}\left(\mathrm{CH}_{2}\right)_{3} \mathrm{OBn}$ $\mathrm{Ph}, n-\mathrm{Bu}, \mathrm{CH}_{2} \mathrm{OAC}$

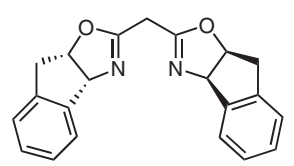

L

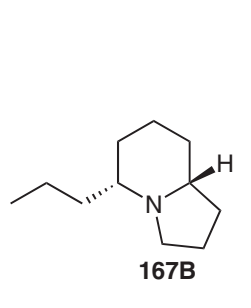

$53 \%$ over 4 steps
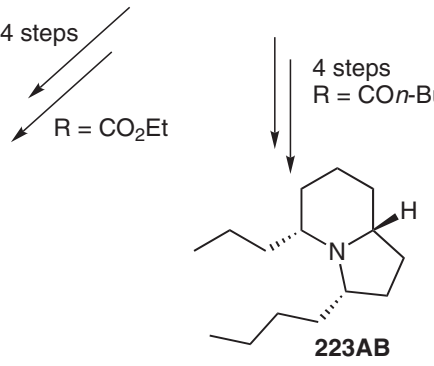

over 4 steps

Significance: A Cu-bisoxazoline catalyzed enantioselective addition of terminal alkynes to $\mathrm{N}$-acylpyridinum salts is reported. The reaction is quite general, proceeds in good yields and poor to excellent ee without 1,4-addition products observed. A carbonyl functionality at the 3-position of terminal alkynes is essential for achieving high enantioinduction. The dihydropyridine products were further converted into 2,6-cis-disubstituted piperidines.
Comment: Piperidines are components of several classes of alkaloids and are prevalent substructures of bioactive molecules (see review below). Previous stereoselective syntheses of dihydropyridines by asymmetric nucleophilic attack onto activated $\mathrm{N}$-acylpyridiniums (D. L. Comins and coworkers J. Am. Chem. Soc. 1999, 121, 2615; C. Marazano and co-workers J. Org. Chem. 1993, 53, 2052) mostly involve the use of chiral pyridine substrates. The present catalytic methodology has the advantage of using readily available starting materials. The utility of this method was demonstrated by the efficient syntheses of the two indolizidines 167B and 223AB.

Review: P. M. Weintraub and co-workers Tetrahedron 2003, 59, 2953. 